His sense of humour is reminiscent of the happy and sometimes boisterous Robert Jones. On one occasion, before he had started making cars, he gave a lift in his recently bought smart coupé to a friend who said on arrival at his home: "You must come in because otherwise my wife will think I have come into a fortune," and he replied promptly "Tell her that you have just got out of one." Again, when a report of his achievements had been read to him he said "The man's a marvel," but with a chuckle, twinkle and with utmost modesty.

In 1904 this young bicycle-maker married a quiet and retiring lady, Elizabeth Maud, who has been his close and stimulating companion throughout his life. They have no children of their own but it has been said with much truth that "Nuffield made the whole nation his heir." His home is a quiet retreat which he says " recharges my batteries."

On his eightieth birthday the orthopaedic surgeons of Great Britain, the British Commonwealth of Nations and the United States of America pay humble respects and grateful acknowledgment to our friend, supporter and benefactor-Nuffield. EDITOR.

\title{
TREATMENT OF CONGENITAL DISLOCATION OF THE HIP
}

The paper by Somerville and Scott of Oxford in this issue is in keeping with the modern trends in treatment of congenital dislocation of the hip; there is an increasing tendency towards operation, because the long-term results of conservative management have not proved satisfactory. The percentage of satisfactory final results has varied in recorded series from approximately 50 per cent down to 11 per cent (Severin), although in those aged less than three years the proportion is slightly better. It is realised that the condition is a true dysplasia and that subluxation or luxation is but a part of the pathology; it is also appreciated that a treated hip with good function may not retain its function over the years if an appreciable anatomical blemish is present. Obviously the ideal aim is a perfect anatomical and functional result with the least expenditure of effort and time and with the greatest safety.

In general the treatment of congenital dislocation of the hip in the child under five years involves two main hurdles: 1) the concentric reduction of the femoral head into the acetabulum; and 2) its permanent retention there, which can be achieved only by the development, natural or assisted, of the acetabular roof and the correction of any deforming factor such as anteversion of the femoral neck with or without valgus deformity. Some dislocated hips are irreducible by closed methods. The necessary open reduction is best carried out forthwith rather than after several unsuccessful attempts at closed reduction. The causes of irreducibility are chiefly soft-tissue obstructions, and these have been well described by Putti (1935) and more recently by Platt (1956). The latter laid more emphasis on a hypertrophied ligamentum teres and a large femoral head than on abnormal attachment of the capsule to the femoral neck and the presence of an adherent plug of fibro-fatty tissue in the acetabulum. These latter two structures, in the writer's experience, are a more common finding. An hour-glass contraction of the capsule is no longer conceded, but undoubtedly a contracted ilio-psoas tendon often indents the capsule and may, by itself, be the most important obstacle to reduction. The inverted limbus (acetabular labrum), although it may be a contributing factor in preventing reduction, is not in itself of major importance. How then can the view put forward by Somerville and Scott in their important contribution to this Journal be reconciled with these findings at operation? Reduction implies that the femoral head enters the acetabulum, but it may be placed concentrically or eccentrically. It appears that excision of part or all of the limbus, as advocated, allows an eccentric reduction to be converted easily and safely to a concentric one. It should be emphasised that a truly irreducible dislocation, in which the head will not descend to the level of the acetabulum or enter it, can never be reduced by the simple means of removing the inverted limbus.

Arthrography has proved reliable, but it is not essential in the management of congenital subluxation or dislocation. Its employment can give valuable information about the size of

VOL. 39 B, NO. 4, NOVEMBER 1957 
the cartilaginous femoral head, the soft-tissue disposition, and whether a given reduction is concentric or eccentric. It should not be used routinely, but should be restricted to the few occasions on which information is necessary about the position or the size of the cartilaginous head in relation to the acetabulum. In arthrography an anterior approach seems to find favour with most orthopaedic surgeons, but the writer has found the perineal route much easier.

A common finding at operation in an older child whose acetabular roof has not developed in spite of an apparently satisfactory reduction has been the presence of a compressed, inverted limbus between the head and the acetabular roof. Is it not conceivable that the presence of this inverted limbus through the years has interfered with the natural ossification of the acetabular roof? Somerville and Scott think so and produce some radiographic evidence in favour of their hypothesis; it appears that removal of a fair sized inverted limbus in the younger child allows better development of the acetabular roof. Will excision of the limbus therefore make the operation of acetabuloplasty unnecessary in the young child? This may be so except on the rare occasions when an open reduction is found to be unstable because of acetabular deficiency or a large femoral head cannot be covered by the acetabulum. If the disproportion between the femoral head and acetabulum is excessive an operation in two stages is sometimes useful: first implantation of bone in the ilium above the hip, and then, three months later, fashioning the acetabuloplasty. In the older child acetabuloplasty will still be necessary when instability and the danger of redislocation is due to a sloping acetabular roof.

Epiphysitis of the femoral ossific nucleus unfortunately occurs all too often; severe degrees often mar the final result. It has never been satisfactorily explained. Many hypotheses contain an element of truth, but not one contains the whole truth. The epiphysitis has been considered to be part of the dysplasia, but this does not explain why it sometimes occurs in the opposite, undislocated hip. Manipulative reduction has been incriminated, and may well be a contributory (but not the main) factor because the incidence of epiphysitis has lessened, but by no means disappeared, with the use of more gradual methods of reduction by traction. Epiphysitis appears to be less frequent after open reduction, and it may well be that removal of the soft tissue including the inverted limbus allows the femoral head to be placed in the acetabulum with less tension than occurs in a closed reduction.

Anteversion of the femoral neck and its significance as a cause of redislocation have long been recognised, but, in this country particularly, its correction has been considered necessary only within the last twenty years. According to Le Damany (1908) and Badgley (1949), the primary cause of the dislocation is an anteversion of the femoral neck, and all soft-tissue abnormalities are secondary. Many would disagree. It is not possible clinically to measure with any accuracy the amount of anteversion; that is not important provided that the presence of anteversion is recognised and its adequate correction by osteotomy of the femoral shaft undertaken. The method described by Somerville and Scott has been carried out for a longer time in other orthopaedic centres in this country, although not routinely. Recurrence of anteversion requiring further operative treatment may rarely occur.

Valgus deformity of the femoral neck, if present, can and should be corrected by wedge resection at the time of the osteotomy. That procedure enables the femoral head to occupy a concentric position in relation to the rest of the pelvis.

After the age of three it is doubtful whether conservative treatment is worth a trial. Between the ages of three and eight a subluxation should be dealt with by closed reduction, which is generally easily performed, followed by acetabuloplasty with, if need be, correction of any anteversion. A true dislocation, between the ages of three and five would require open reduction, but between the ages of five and ten a dislocation is best dealt with by a capsular arthroplasty along the lines advocated by Hey Groves (1928) and modified by Colonna (1936).

Conservative treatment has had a long trial; it " has not produced the goods"; its era is slowly passing and will be replaced eventually by the routine operative treatment of congenital 
dislocation of the hip. Satisfactory results in a much larger percentage of patients should be obtained-and with a much shorter duration of treatment-than by purely conservative measures.

DAVID TREVOR.

\section{REFERENCES}

Badgley, C. E. (1949): Etiology of Congenital Dislocation of the Hip. Journal of Bone and Joint Surgery, 31-A, 341.

Colonna, P. C. (1936): An Arthroplastic Operation for Congenital Dislocation of the Hip-a Two Stage Procedure. Surgery, Gynecology and Obstetrics, 63, 777.

Groves, E. W. Hey (1928): The Treatment of Congenital Dislocation of the Hip-Joint, with Special Reference to Open Operative Reduction. In The Robert Jones Birthday Volume, p. 73. London: Humphrey Milford Oxford University Press.

Le Damany, P. (1908): Die angeborene Hüftgelenksverrenkung. Ihre Ursachen-Ihre Mechanismus-Ihre anthropologische Bedeutung. Zeitschrift für Orthopädische Chirurgie, 21, 129.

Platt, Sir H. (1956): Congenital Dislocation of the Hip: the Rôle of Open Reduction. In Modern Trends in Orthopaedics (Second Series), p. 93. Edited by Sir H. Platt. London: Butterworth \& Co. (Publishers) Ltd. Putri, V. (1935): Anatomia della Lussazione Congenita dell'Anca. Bologna: L. Cappelli.

Severin, E. (1941): Contribution to the Knowledge of Congenital Dislocation of the Hip Joint. Late Results of Closed Reduction and Arthrographic Studies of Recent Cases. Acta Chirurgica Scandinavica, 84, Supplementum 63.

\section{THE MAINTENANCE OF TRAUMATIC ARTERIAL SPASM}

An interesting paper by A. Benjamin in this issue of the Journal again discusses the idea that oedema in swollen muscles is an important factor in the pathology of traumatic arterial spasm and therefore in the production of Volkmann's ischaemic contracture. Benjamin does not blame oedema for causing the arterial obstruction which precedes the contracture, nor does he blame oedema at the site of the fracture for maintenance of the spasm; he suggests instead that " tension from oedema in a neighbouring fascial compartment may be the stimulus that maintains the spasm." He therefore advises wide decompression of swollen muscles away from and distal to the site of the fracture, in the hope that this will help to overcome the spasm by removing one factor which keeps it up. In support of this view he describes three cases, in each of which exploration of injured limbs some hours after the injuries demonstrated the presence of oedema in distal muscles and in which, he claims, decompression of that oedema helped in the restoration of the arterial circulation.

This suggestion cannot, of course, be disproven. It therefore must not be rejected. Readers will, however, decide for themselves whether or not the idea is adequately supported by Benjamin's evidence. His first patient showed the well known and welcome phenomenon of relaxation of arterial spasm during an operation. The fact that this relaxation occurred immediately after division of deep fascia distal to the occluded artery does not, of course, imply a casual relationship, nor does Benjamin postulate any mechanism, reflex or other, by which such a cause could operate. In his second case, is it quite fair to attribute the recovery of the circulation to the muscle decompression? The artery relaxed twenty-five minutes later, and after several other manipulations had been employed. The third case, in which the affected artery was not seen and in which the systemic blood pressure was not recorded, can hardly be regarded as a source of conclusive evidence.

So the debate must continue. Benjamin may be right; further evidence will show. Let us, however, beware of attractive theories which may perhaps be accepted because they cannot be rejected. Surgery has been led astray too often by just this fallacy.

\section{Ll. GRIfFIThS.}

